\title{
The Investigation on Flow Behavior of Powder Metallurgy Ti-10V-2Fe-3Al Alloy Using the Prasad Stability Criterion
}

\author{
KRYSTIAN ZYGUŁA, MAREK WOJTASZEK, OLEKSANDR LYPCHANSKYI, \\ TOMASZ ŚLEBODA, GRZEGORZ KORPAŁA, and ULRICH PRAHL
}

\begin{abstract}
The hot deformation behavior of Ti-10V-2Fe-3Al alloy obtained by the powder metallurgy (PM) method was investigated. Material for the research was produced by blending of elemental powders followed by uniaxial hot pressing. Thermomechanical tests of Ti-10V-2Fe-3Al compacts were carried out to determinate the stress-strain relationships at the temperature range of $800{ }^{\circ} \mathrm{C}$ to $1000{ }^{\circ} \mathrm{C}$ and strain rate between 0.01 and $10 \mathrm{~s}^{-1}$. Based on the dynamic material model (DMM) theory, processing maps at constant strain value were developed using data obtained from hot compression tests. The processing maps were elaborated for the final strain value, which was 0.9 , and with flow instability criterion domains applied to it. Two critical regions associated with the flow behavior of the investigated material were revealed. Microstructural changes during hot deformation at various temperatures and strain rates were discussed. The correlation between calculated efficiency of power dissipation, flow instability criterion, and microstructure evolution was determined. The presence of defects was confirmed in regions predicted by the instability maps. The microstructure of the investigated alloy, corresponding to the high efficiency of power dissipation characterized by the occurrence of dynamic recrystallization (DRX) phenomena, was also shown. Additionally, average hardness values in relation to variable process parameters were designated. Based on the conducted studies and analysis, processing windows for $\mathrm{Ti}-10 \mathrm{~V}-2 \mathrm{Fe}-3 \mathrm{Al}$ alloy compacts were proposed.
\end{abstract}

https://doi.org/10.1007/s11661-019-05434-3

(C) The Author(s) 2019

\section{INTRODUCTION}

Low relative density, high specific strength, and fracture toughness, as well as good resistance to creep and corrosion, are the reasons that titanium alloys are widely used in automotive and aircraft industries. Also, such alloys are widely used in medicine as bone-replacement prosthesis and dental implants and instruments due to the biocompatibility of titanium. ${ }^{[1-4]} \beta$ titanium alloys show favorable strength to density ratio, combined with good ductility and attractive processing features such as deep hardenability and forging performance. ${ }^{[5]}$ Nowadays, the most often applied $\beta$ titanium alloys are $\mathrm{Ti}-10 \mathrm{~V}-2 \mathrm{Fe}-3 \mathrm{Al}$ (Ti-10-2-3), developed in

KRYSTIAN ZYGULA, MAREK WOJTASZEK, OLEKSANDR LYPCHANSKYI, and TOMASZ SLEBODA are with the Faculty of Metals Engineering and Industrial Computer Science, AGH University of Science and Technology, Al. A. Mickiewicza 30, 30-059 Krakow, Poland. Contact email: kzygula@agh.edu.pl GRZEGORZ KORPALA and ULRICH PRAHL are with the Institut für Metallformung, TU Bergakademie Freiberg, 4 Bernhard-von-Cotta-Straße, 09596 Freiberg, Germany.

Manuscript submitted April 26, 2019.

Article published online September 9, 2019
1970 by Timet Company, and Ti-5Al-5Mo-5V-3Cr (Ti-5553). Both of these alloys find their applications in the aircraft industry, especially as landing gear in the Boeing 777 series and Airbus A-380. ${ }^{[2,6]}$ Moreover, $\beta$ titanium alloys are increasingly replacing steel components, which results in weight reduction and decreased working costs. ${ }^{[7]}$

Nevertheless, titanium alloys are considered very expensive to produce compared to common construction materials such as aluminum alloys or stainless steels. The conventional route assumes a complex and multistep process of vacuum remelting of titanium sponge followed by forging, heat treatment, and, in the case of titanium alloys, the relatively expensive machining process. ${ }^{[8]}$ In order to reduce costs, methods based on powder metallurgy (PM) are considered promising. Recently, many researchers have been focused on developing a cost-effective technique to obtain titanium products from consolidated powders. Different approaches, such as hot isostatic pressing of gas-atomized powder, ${ }^{[9,10]}$ hot or cold pressing followed by sintering of blended elemental powders $(\mathrm{BEPM}),{ }^{[11-14]}$ and novel selective laser melting techniques, are proposed to prepare titanium alloy with 
specified chemical composition. ${ }^{[15-17]}$ Regardless of the methods mentioned previously, materials obtained by PM techniques have high relative density and similar mechanical properties as titanium alloys with an equivalent chemical composition produced by conventional route. ${ }^{[18]}$

Understanding the microstructure and mechanical behavior of $\beta$ titanium alloys in a wide range of temperatures and strain rates is crucial to developing suitable thermomechanical processing parameters. Numerous studies mention that the size, amount, morphology, and location of $\alpha$ phase in the initial material and $\alpha^{\prime \prime}$ phase after deformation have a significant influence on the mechanical properties. ${ }^{[11,19,20]}$ The $\alpha$-lamellar microstructure retained after hot processing can successfully increase the fracture toughness but negatively influence ductility. Nevertheless, an appropriate schedule of thermomechanical processing may result in significant microstructure evolution. The effect of variable temperatures and strain rates on changes in $\alpha$ phase morphology was previously observed. ${ }^{[21,22]}$ Qin et al. ${ }^{[23]}$ demonstrated the remodeling of Ti-5553 alloy microstructure from lamellar to bimodal in subtransus conditions and pointed out the role of dynamic recrystallization (DRX) in the formation of such structure. On the other hand, Zhao et al..$^{[2]}$ indicated that during supertransus deformation of Ti-10-2-3 alloy, dynamic recovery (DRV) more often occurred as a mechanism of restoration than dynamic recrystallization, which may have a significant influence on further mechanical properties.

Moreover, for controlling and predicting the flow behavior of the material during hot deformation carried out at various combinations of temperatures and strain rates, processing maps based on dynamic material model (DMM) theory can be developed. ${ }^{[25,26]}$ Prasad et al. ${ }^{[27]}$ proposed applying processing maps to predict microstructural behavior of hot-deformed material and designating the combination of processing parameters as value of strain, temperature, and strain rate, which are the most beneficial for plastic deformation of the proposed material. This work discusses the flow behavior and microstructural changes of $\mathrm{Ti}-10 \mathrm{~V}-2 \mathrm{Fe}-3 \mathrm{Al}$ alloy obtained by blended elemental PM approach as well as the development of processing windows based on DMM theory.

\section{EXPERIMENTAL PROCEDURE}

The starting material used for the experimental research was Ti-10V-2Fe-3Al (Ti-10-2-3) alloy compact made by hot pressing a mixture of elemental titanium, vanadium, aluminum, and iron powders with nominal composition given in Table I. First, the mixture of elemental powders was blended for 2 hours in industrial conditions and was then compacted at $1200{ }^{\circ} \mathrm{C}$ under a pressure of $25 \mathrm{MPa}$ under argon atmosphere. After compaction, the relative density of the obtained compacts was measured by the Archimedes method.
Energy-dispersive X-ray spectroscopy (EDS) analysis was performed using a Hitachi HM-3000 (Hitachi, Ltd., Tokyo, Japan) scanning microscope, to examine the Ti-10-2-3 alloy mixture and to identify the morphology and location of its ingredients. In order to identify the $\beta$-transus temperature, dilatometric tests were performed using a Bähr DIL 805 A/D (BÄHR Thermoanalyse $\mathrm{GmbH}$, Hüllhorst, Germany) quenching and forming dilatometer. Specimens were heated with a heating rate of $2.5^{\circ} \mathrm{C} \mathrm{s}^{-1}$ to $1000{ }^{\circ} \mathrm{C}$, held at this temperature for 300 seconds, and cooled to room temperature with various cooling rates.

The hot deformation tests were carried out on a thermomechanical simulator Bähr MDS 830 (BÄHR Thermoanalyse GmbH, Hüllhorst, Germany). Tests were performed at temperatures of $800{ }^{\circ} \mathrm{C}, 900{ }^{\circ} \mathrm{C}$, $950{ }^{\circ} \mathrm{C}$, and $1000{ }^{\circ} \mathrm{C}$ and at strain rates of $0.01,0.1,1$, and $10 \mathrm{~s}^{-1}$ under argon atmosphere. Specimens with dimensions of $10 \mathrm{~mm}$ in diameter and $12 \mathrm{~mm}$ in height were heated with a heating rate of $2.5^{\circ} \mathrm{C} \mathrm{s}^{-1}$ and then held at deformation temperature for 10 seconds. After hot compression, the material was cooled with compressed air. A light microscope Leica DM4000M (Leica Microsystems GmbH, Wetzlar, Germany) was used to analyze the microstructure of unprocessed and hot-deformed titanium alloy compact. Ground and polished cross sections were etched with Kroll's reagent consisting of 2 vol pct HF, 2 vol pet $\mathrm{HNO}_{3}$, and 94 vol pet $\mathrm{H}_{2} \mathrm{O}$. Vickers hardness tests with a load of $19.6 \mathrm{~N}$ were conducted on as-compacted as well as on hot-pressed material. The average hardness was measured on cross sections of compressed samples.

\section{RESULTS}

\section{A. Characterization of Initial Material}

Figure 1(a) shows the morphology of the Ti-10-2-3 powder mixture used in a hot pressing process. Irregular titanium and iron particles had a rough surface. Small size aluminum particles were most often inserted on the surface of other mixture ingredients as a result of the blending process. Vanadium particles were elongated, their size was up to $250 \mu \mathrm{m}$, and they had a smooth surface. The results of EDS analysis are shown in Figure 1(b) and Table I. The proposed blending process resulted in uniform distribution of elemental powders in the mixture. The chemical composition measured by the EDS method corresponded to the chemical composition of Ti-10-2-3 alloy.

In reference to the theoretical density of solid material, which was $4.65 \mathrm{~g} \mathrm{~cm}^{-3}$, ${ }^{[28]}$ the measured relative density of Ti-10-2-3 alloy compact was 99.4 pct. Microstructural observations of as-pressed compact confirmed that the investigated material had no significant porosity and was characterized by homogenous microstructure. It can be observed that the microstructure of Ti-10-2-3 alloy compact (Figure 2) was mainly composed of massive lamellar $\alpha$ grains in the $\beta$ phase 
Table I. Nominal Chemical Composition of Ti-10-2-3 Alloy and Average Results from EDS Analysis of the Mixture of Elemental Powders (Both in Weight Percent)

\begin{tabular}{llllllllr}
\hline & $\mathrm{V}$ & $\mathrm{Al}$ & $\mathrm{Fe}$ & $\mathrm{O}$ & $\mathrm{H}$ & $\mathrm{N}$ & $\mathrm{C}$ & $\mathrm{Ti}$ \\
\hline Nominal Composition, pct & 9 to 11 & 2.6 to 3.4 & 1.6 to 2.2 & $<0.13$ & $<0.0125$ & $<0.05$ & $<0.05$ & bal. \\
EDS Results, pct & 10.2 & 3.1 & 1.7 & - & - & - & - & bal. \\
\hline
\end{tabular}
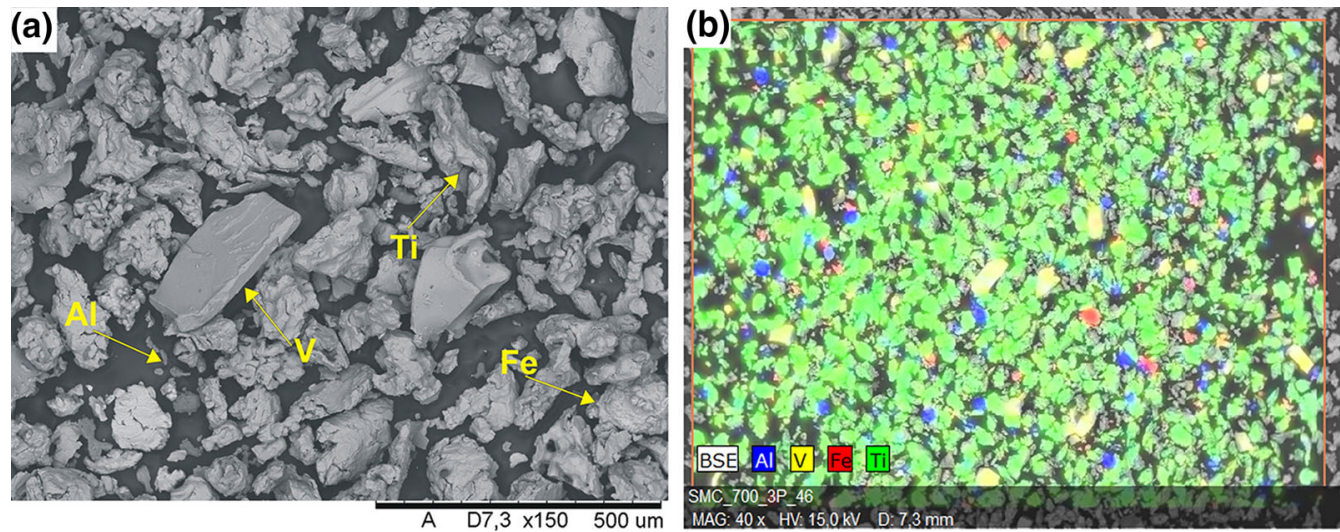

Fig. 1-(a) Morphology and (b) results from EDS analysis of Ti-10-2-3 alloy elemental powders mixture.

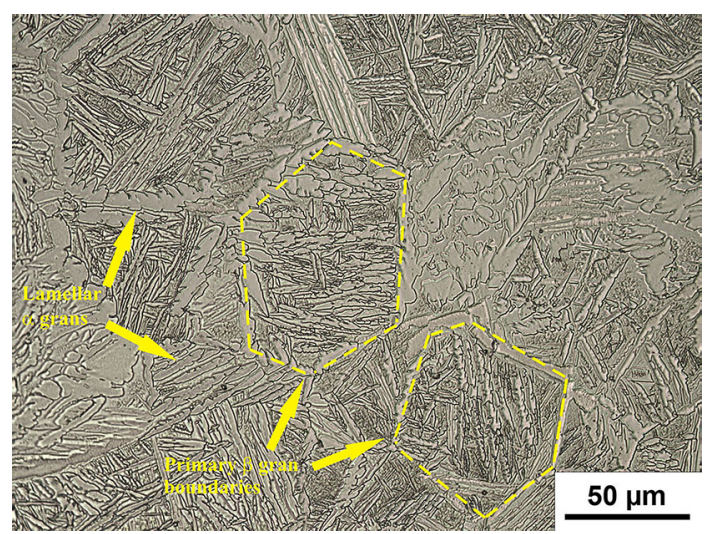

Fig. 2-Microstructure of as-pressed Ti-10-2-3 alloy compact.

matrix located on and within primary $\beta$ grain boundaries.

A sample cut from as-pressed compact was subjected to the dilatometric test. Figure 3 shows the dilatometric curve for Ti-10-2-3 alloy tested at a cooling rate of $0.1^{\circ} \mathrm{C} \mathrm{s}^{-1}$. Sample length changes in the function of temperature are nonlinear. The deviation from linearity indicates the phase transformation and microstructural changes during cooling from high temperature. To analyze dilatometric responses more precisely, the derivative of the dilatometric curve was calculated. Two major effects were observed. The first one was shrinkage occurring at temperatures between $555^{\circ} \mathrm{C}$ and $665{ }^{\circ} \mathrm{C}$, and the second was expansion above $855^{\circ} \mathrm{C}$.

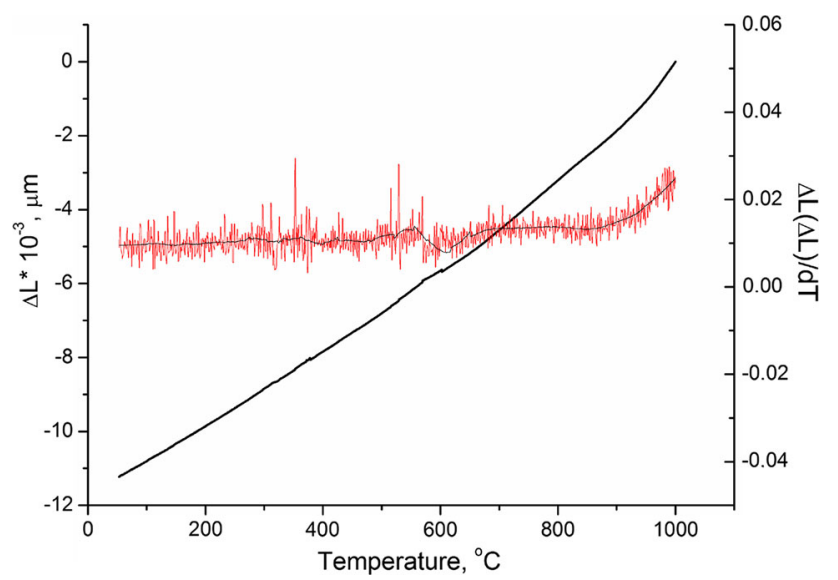

Fig. 3-Dilatometric curve for Ti-10-2-3 alloy compact tested at a cooling rate of $0.1^{\circ} \mathrm{C} \mathrm{s}^{-1}$ and its derivative.

\section{B. Flow Behavior}

The true stress-strain curves obtained from isothermal compression tests of Ti-10-2-3 alloy compacts at various temperatures and strain rates are shown in Figure 4. The material was tested at the temperature below $\beta$-transus $\left(800{ }^{\circ} \mathrm{C}\right)$ and in a wide temperature range above $\beta$-transus $\left(900{ }^{\circ} \mathrm{C}, 950{ }^{\circ} \mathrm{C}\right.$, and $\left.1000^{\circ} \mathrm{C}\right)$. The observations of stress-strain curves indicated high sensitivity of the material to changes in deformation conditions such as temperature and strain rate. As could be expected, due to increasing temperature, the flow stress decreased. At the lower temperature, continuous flow softening preceded by the stress peak was clearly observed. Irrespective of strain rate, the flow 


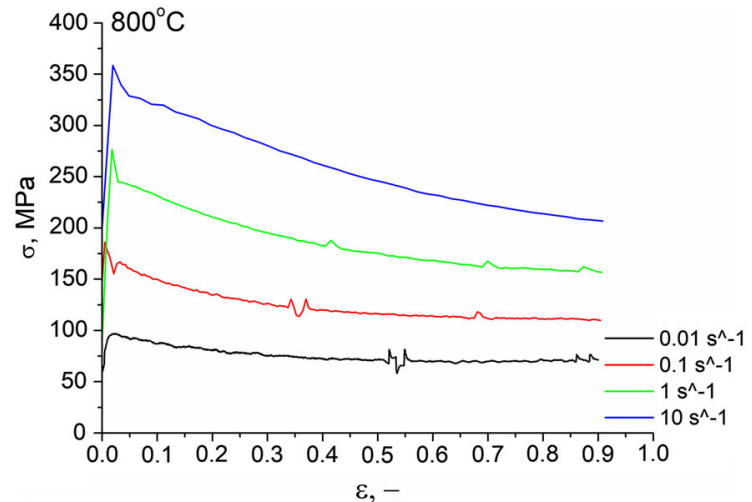

(a)

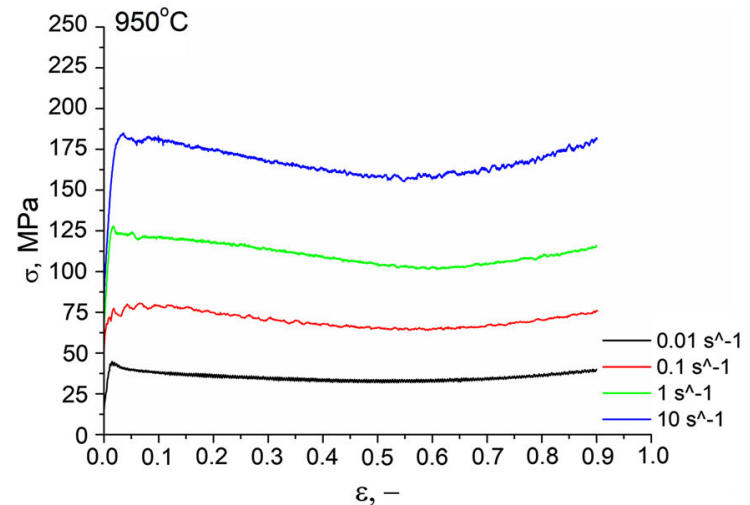

(c)

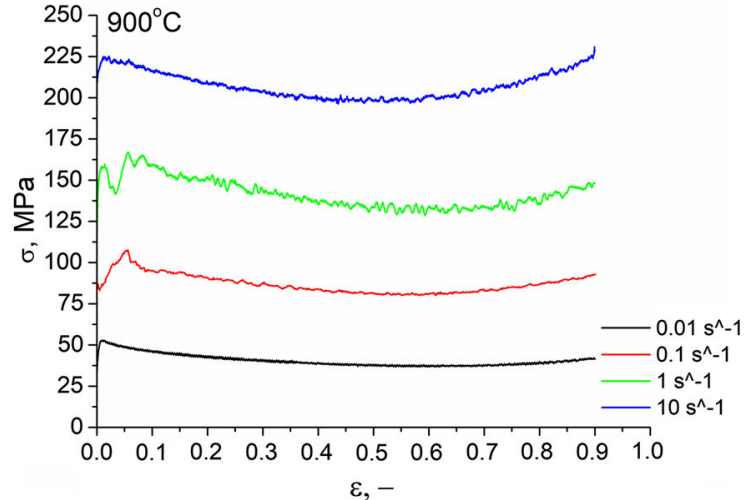

(b)

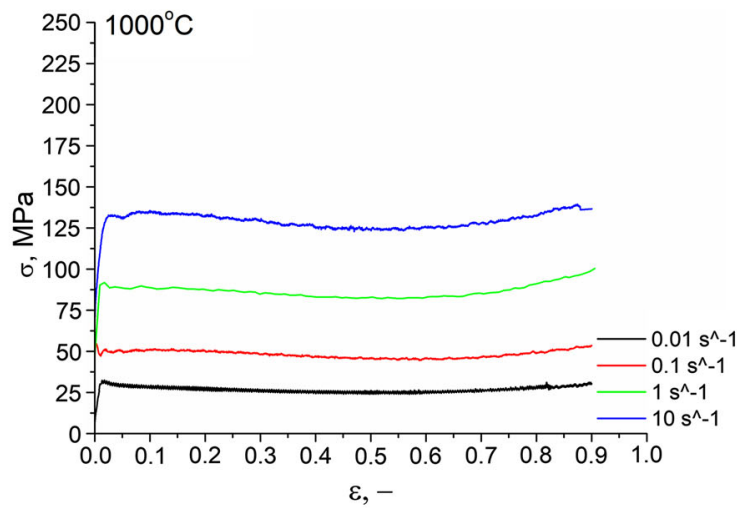

(d)

Fig. 4-True stress-true strain curves for Ti-10-2-3 alloy compacts obtained in compression tests at various strain rates and temperatures: $(a)$ $800{ }^{\circ} \mathrm{C},(b) 900{ }^{\circ} \mathrm{C},(c) 950{ }^{\circ} \mathrm{C}$, and $(d) 1000{ }^{\circ} \mathrm{C}$.

softening effect decreased with increasing temperature of deformation and flow behavior of material became more stable.

\section{Processing Maps}

Processing maps based on the theory of DMM, developed by Prasad et al., ${ }^{[27]}$ were used to describe the dynamic metallurgical processes and workability of Ti-6242 alloy during hot forming. This method is based on the assumption that total power (Eq. [1]) absorbed by a material during the deformation process is divided into two parts: $G$ (Eq. [2]) and $J$ (Eq. [3]).

$$
\begin{gathered}
P=\sigma \cdot \dot{\varepsilon}=G+J \\
G=\int_{0}^{\dot{\varepsilon}} \sigma \cdot d \dot{\varepsilon} \\
J=\int_{0}^{\sigma} \dot{\varepsilon} \cdot d \sigma
\end{gathered}
$$

where $G$ is the dissipation component representing a part of the energy that is converted into heat during plastic deformation and $J$ is the component representing the dissipation of energy as the result of the microstructural changes dynamically occurring during deformation, such as phase transformation, DRX, or grain refinement.

The processing maps are composed of parameter $\eta$ (Eq. [4]), which represents the efficiency of the power dissipation, and parameter $\xi$ (Eq. [5]) representing flow instability criterion:

$$
\begin{gathered}
\eta=\frac{J}{J_{\max }}=\frac{2 m}{m+1} \\
\xi=\frac{\partial \ln \left(\frac{m}{m+1}\right)}{\partial \ln (\dot{\varepsilon})}+m<0
\end{gathered}
$$

where $m$ (Eq. [6]) is the strain rate sensitivity parameter defined at a constant value of temperature and strain as

$$
m=\left(\frac{\partial \log \sigma}{\partial \log \dot{\varepsilon}}\right)_{T, \varepsilon}
$$

If parameter $\xi$ has a negative value, microstructural flow instabilities, such as adiabatic shear bands (ASBs), localization of deformation, or cracks, may occur. On a processing map, such a region is considered as unsafe. 
On the other hand, most safe regions are those where the efficiency of the power dissipation $\eta$ takes the highest values. In those regions, DRX and superplasticity may occur.

Based on the fact that during hot forming processes strain value is not uniform in the volume of the material and it changes over the process, the full description of favorable deformation parameters at intermediate strain values should be evaluated. The processing maps of as-pressed Ti-10-2-3 alloy compact at different strain values with a strain rate range of 0.01 to $10 \mathrm{~s}^{-1}$ and temperature range from $800{ }^{\circ} \mathrm{C}$ to $1000^{\circ} \mathrm{C}$ are shown in Figure 5. The counter lines represent the efficiency of the power dissipation $(\eta)$ in percentage, and the shadowed domain indicates the flow instability region $(\xi$, where $\xi(\dot{\varepsilon})<0)$. A map for a true strain value of 0.1 corresponds to the peak stress and softening effect observed on the flow stress curves, and the true strain value of 0.5 corresponds to a steady-state behavior of the investigated material observed on the flow stress curves.
Figure 5(c) shows the state corresponding to the true stain value of 0.9 , which was adopted as the final strain value during hot compression tests.

\section{Microstructural Characterization}

Microstructures corresponding to instability regions marked as gray domains in Figure 5(e) are shown in Figure 6. Deformation in low temperatures and high strain rate (Figure 6(a)) results in flow localization. Retained $\alpha$ phase grains were elongated and no significant DRX effects can be observed. Such state promotes a decrease of formability of the material and can result in debonding and crack propagation. ${ }^{[29]}$ Moreover, the side view of the sample compressed at the temperature of $800{ }^{\circ} \mathrm{C}$ and strain rate of $10 \mathrm{~s}^{-1}$ was shown in Figure 6(c). It can be seen that there are visible cracks on the surface of the specimen deformed at parameters corresponding to the instability region. The microstructure of Ti-10-2-3 alloy compact compressed at $1000{ }^{\circ} \mathrm{C}$

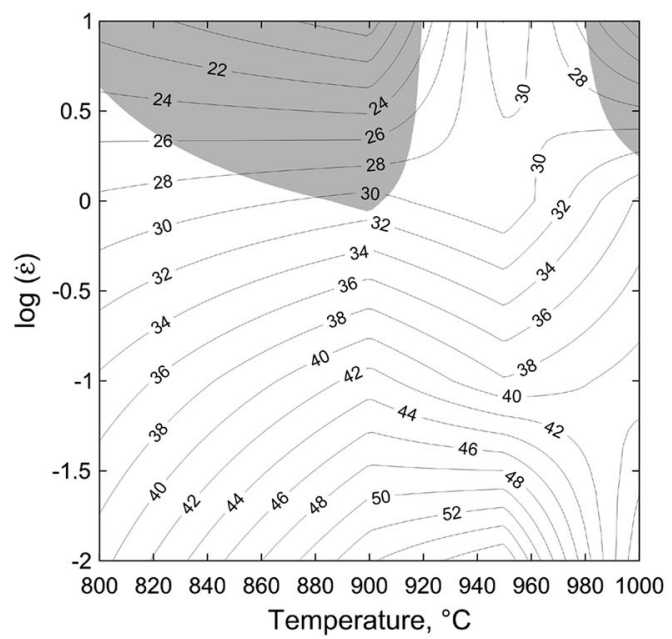

(a)

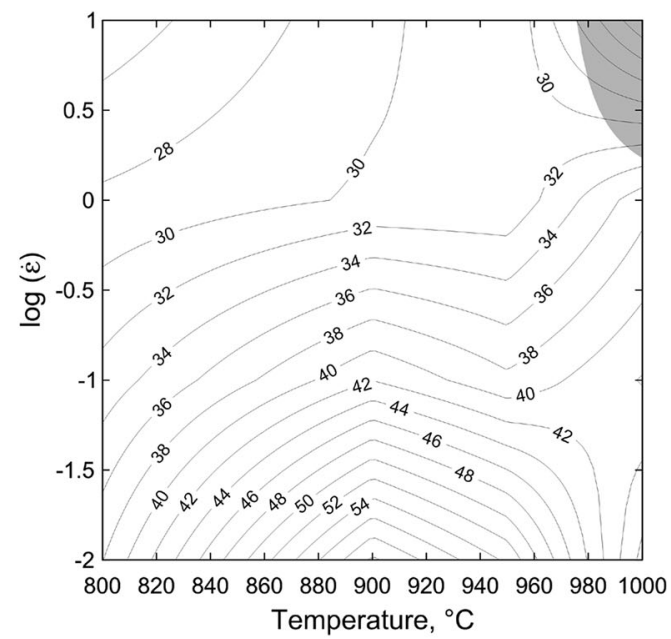

(b)

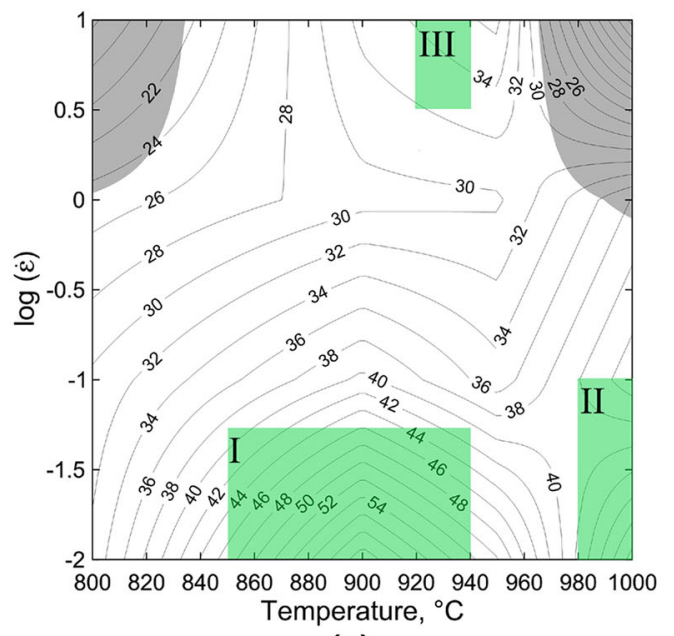

(c)

Fig. 5-Processing maps for Ti-10-2-3 alloy compact developed for a true strain of $(a) 0.1,(b) 0.5$, and (c) 0.9. Applied green domains refer to the chosen processing windows. 

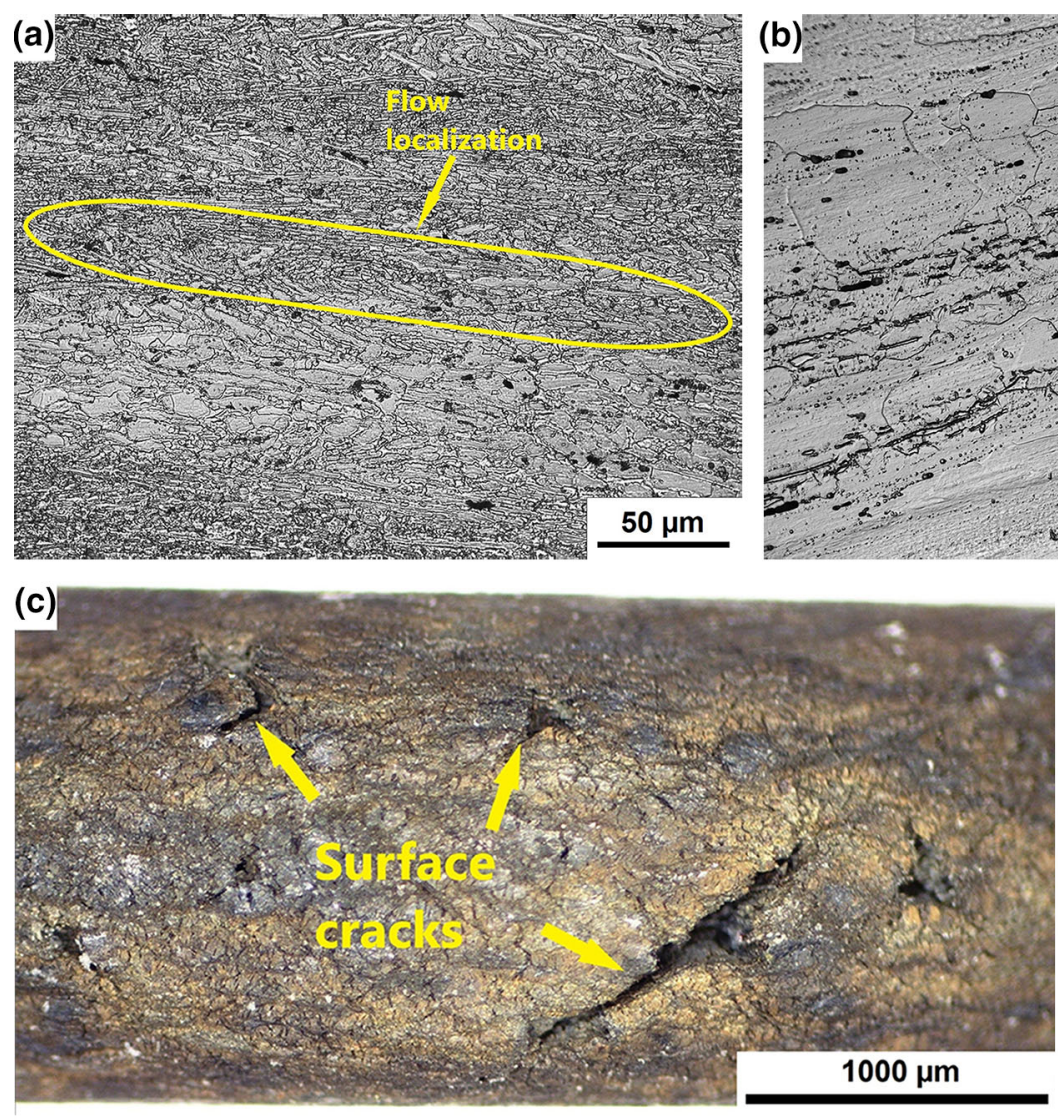
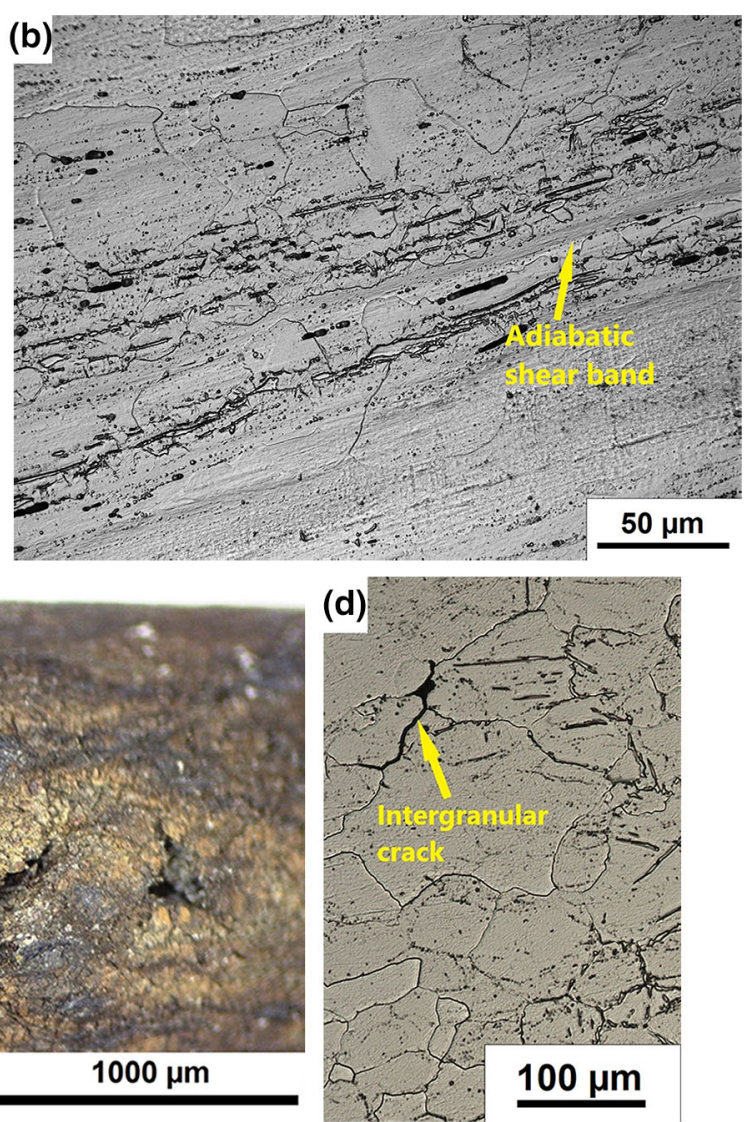

Fig. 6-Microstructure of Ti-10-2-3 alloy compact deformed in instability areas at (a) $800{ }^{\circ} \mathrm{C}$ and a strain rate $10 \mathrm{~s}^{-1},\left(\right.$ b) $1000{ }^{\circ} \mathrm{C}$ and a strain rate $10 \mathrm{~s}^{-1},(c)$ crack on the surface of specimen deformed at $800{ }^{\circ} \mathrm{C}$ and a strain rate $10 \mathrm{~s}^{-1}$, and $(d)$ microcrack of Ti-10-2-3 alloy compact deformed at $1000{ }^{\circ} \mathrm{C}$ and at a strain rate $10 \mathrm{~s}^{-1}$.
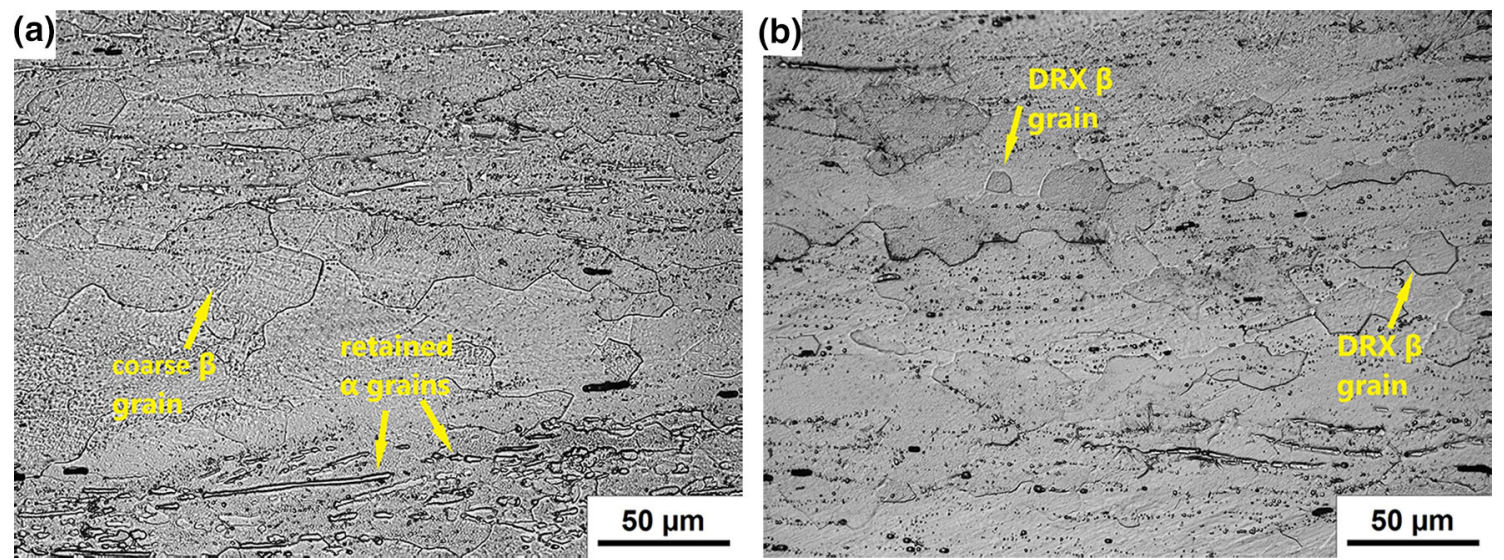

Fig. 7-Microstructure of Ti-10-2-3 alloy compact deformed at $(a) 900{ }^{\circ} \mathrm{C}$ and at a strain rate $0.01 \mathrm{~s}^{-1}$ and $\left(\right.$ b) $1000{ }^{\circ} \mathrm{C}$ and a strain rate $0.1 \mathrm{~s}^{-1}$.

and at a strain rate of $10 \mathrm{~s}^{-1}$ is shown in Figure 6(b). The microstructure reveals ASBs, which are typical for the material deformed with a high strain rate. Such ASBs promote the formation of microcracks along them, which leads to failure of the material. Figure 6(d) shows another microstructure of Ti-10-2-3 alloy deformed at $1000{ }^{\circ} \mathrm{C}$ and at a strain rate of $10 \mathrm{~s}^{-1}$ with intergranular crack formed along the grain boundary.
The microstructures of the specimens compressed at a temperature of $900{ }^{\circ} \mathrm{C}$ and at a strain rate of $0.01 \mathrm{~s}^{-1}$ as well as at $1000{ }^{\circ} \mathrm{C}$ and $0.1 \mathrm{~s}^{-1}$ are shown in Figure 7. The chosen parameters correspond to the high-power dissipation value; thus, superplasticity or DRX is expected and workability of the material will be improved. It should be noted that superplasticity occurs when the $\eta$ value is over 60 pct and DRX takes place 
when the $\eta$ value is between 30 and 50 pct. ${ }^{[26,30]}$ The microstructure corresponding to peak efficiency is shown in Figure 7 (a). At $900{ }^{\circ} \mathrm{C}$ and a low strain rate, DRX occurs and coarse $\beta$ grains are formed. In comparison to the initial microstructure (Figure 2), no lamellar structures are observed and only a small amount of retained $\alpha$ grains elongated toward the flow direction are left. Similar effects were noted during the analysis of the microstructure of Ti-10-2-3 alloy obtained during hot compression at $1000{ }^{\circ} \mathrm{C}$ and at a strain rate of $0.1 \mathrm{~s}^{-1}$ (Figure 7(b)), where fully recrystallized, uniaxial grains were visible. A similar observation was noted by Lin et al.,$^{[31]}$ where the volume fraction of the $\alpha$ phase drastically decreased at the deformation temperature over the $\beta$-transus for Ti-55511 alloy. Moreover, significant microstructural defects, related to flow localization or ASB, and macrostructural defects, such as cracks on the surface of the sample, were not observed in the material after hot deformation performed with the combination of the parameters corresponding to the regions considered as stable according to Figure 5.

\section{E. Hardness Measurements}

Changes in the hardness of the investigated material, depending on the temperature and strain rate, are presented in Figure 8. In comparison to the initial material, the average hardness of hot-deformed material increased from 330 to $390 \mathrm{HV}_{2}$, depending on the process parameters. Hardness changes are mostly related to the changes in the microstructure of hot-deformed material. A large number of fragmented $\alpha$ lamellas retained after compression at low temperature result in an increase of hardness. Due to the increase of deformation temperature, the hardness of the material decreases, related to the occurrence of DRV and $\beta$ grain

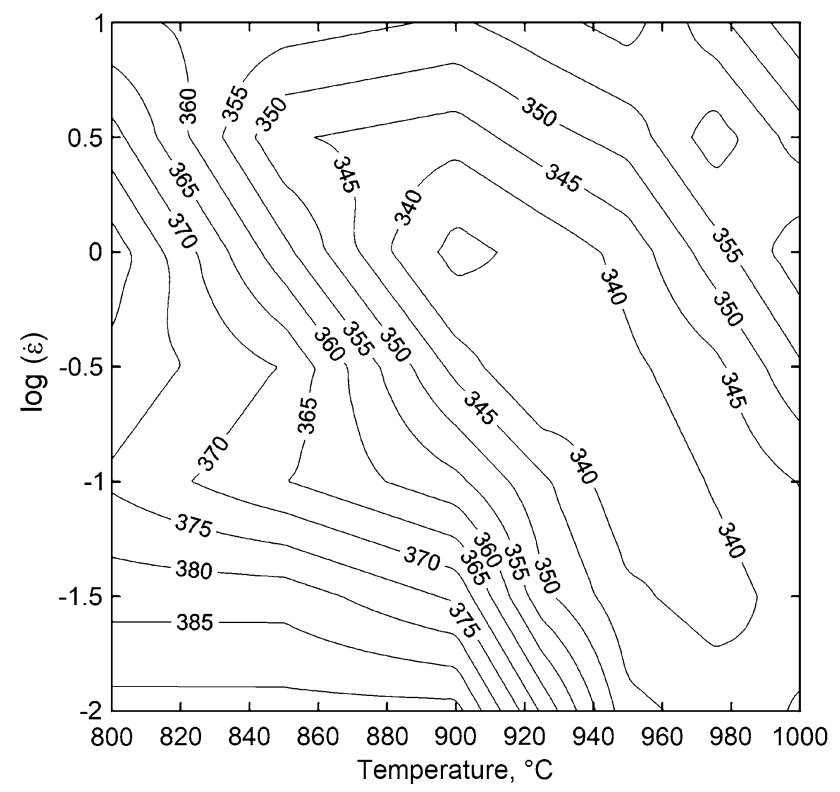

Fig. 8-Hardness map for Ti-10-2-3 alloy compact deformed at various temperatures and strain rates. growth. Nevertheless, at the temperature range of $900{ }^{\circ} \mathrm{C}$ to $940{ }^{\circ} \mathrm{C}$ and at a low strain rate, a relatively high hardness value and dense distribution of isoclines correspond to the high value of efficiency of the power dissipation parameter for this set of parameters. The $\eta$ values exceeding 40 pct promote the occurrence of DRX, which results in the formation of fine microstructure and an increase in mechanical properties. Further, an increase in deformation temperature results in extensive $\beta$ grain growth and a decrease in hardness in the deformation temperature range of $940{ }^{\circ} \mathrm{C}$ to $1000{ }^{\circ} \mathrm{C}$. Comparing hardness values obtained for the material deformed previously, at the $\beta$-transus temperature and at high strain rates, to corresponding $\eta$ values, it can be observed that the decrease of hardness may result from the occurrence of DRV, which is a more probable phenomenon for the efficiency of power dissipation values in the range of 28 to 32 pct.

\section{DISCUSSION}

\section{A. Initial Material Features and Flow Characteristics}

The initial microstructure of Ti-10-2-3 alloy compact shown in Figure 2 is characteristic for $\beta$ or near $\beta$ titanium alloys cooled slowly from the $\beta$ phase field. ${ }^{[12]}$ Precipitations first appear inside $\beta$ grains and on their boundaries and then grow to coarse lamellas. Also, acicular $\alpha$ grains arranged perpendicular to each other were noticed. The initial morphology of $\alpha$ grains had a significant influence on subsequent mechanical properties after hot deformation. Breaking down the $\alpha$ lamellar structure and forming homogenized, spherical grains provides better tensile ductility and fracture toughness of the processed titanium alloys. Srinivasu et al. ${ }^{[7]}$ reported that not only different types of $\alpha$ phase morphology but also hot processing depending on the $\beta$-transus temperature had a significant impact on the mechanical properties of the final product.

Dilatometric studies and a literature review allow us to state that the shrinkage, noticeable on the dilatometric curve (Figure 3), was related to microstructure remodeling, which could be related to increasing secondary $\alpha$ fraction due to $\beta \rightarrow$ secondary $\alpha$ transformation and further coarsening of acicular $\alpha$ grains. Some research works point out that the expansion effect determines the starting point of $\beta \leftrightarrow \alpha+\beta$ transformation.${ }^{[1,32]}$ Moreover, oxygen contamination resulting from the method of obtaining the initial material, which was blending of the elementary powders, can lead to disturbance of the $\beta$ stabilizing effect by other alloying elements and an increase of the $\beta$-transus temperature. ${ }^{[33]}$

Various conditions of hot compression tests influenced the flow behavior of the Ti-10-2-3 alloy compact (Figure 4). At high temperature, DRV and DRX may occur earlier, which explains the drop in the softening effect. Yield drop phenomena were observed as increasing with increasing strain rate. Discontinuous yielding occurs in many types of $\beta$ titanium alloys and was previously reported by Philippart and Rack. ${ }^{[34]}$ This 
effect is related to the rapid generation of mobile dislocations at the grain boundaries. It can be observed that strain rate, as well as deformation temperature, had a significant influence on flow behavior. At a constant strain rate, increasing the temperature causes the flow stress to decrease due to the reduction of dislocation density during DRV and DRX processes. Moreover, at higher temperatures, the activation energy of atoms is also higher, which reduces the critical shear stress and facilitates dislocation movement. Large deformation at high-temperature conditions promotes the occurrence of DRV and recrystallization effects, which explains the flow softening phenomena after reaching a stress peak at the early stage of compression. It can also be noticed that flow stress increases more slowly with strain rate at high temperatures. At $800{ }^{\circ} \mathrm{C}$, flow stress increases by $90 \mathrm{MPa}$ when the strain rate increases by an order of magnitude, while at $1000{ }^{\circ} \mathrm{C}$, flow stress increases by $35 \mathrm{MPa}$ when the strain rate increases by an order of magnitude. At temperatures above the $\beta$-transus and at high strain rate, the effect of increasing stress with increasing strain in a stable flow region can be observed. Such a phenomenon was previously reported by Wang et $a l .{ }^{[35]}$ and could be caused by strengthening resulting from the pinning effect. At higher strains, the number of new $\alpha$ phase precipitations is large enough to interact with dislocations and disturb DRV, leading to an increase in flow stress.

\section{B. Domain Characteristics and Microstructural Validation}

The processing maps shown in Figure 5 were developed based on previously analyzed flow curves and they present instability domains, which change with increasing strain values. At the true strain value of 0.1 , shown in Figure 5(a), two instability regions can be observed at a strain rate ranging from 1 to $10 \mathrm{~s}^{-1}$ and in the temperature ranges of $800{ }^{\circ} \mathrm{C}$ to $910{ }^{\circ} \mathrm{C}$ and $980{ }^{\circ} \mathrm{C}$ to $100{ }^{\circ} \mathrm{C}$. A similar effect was noted by Balasubrahmanyam and Prasad ${ }^{[36]}$ for another $\beta$ titanium alloy for low temperatures and at high strain rates. The flow curves, corresponding to this area of the processing map, are characterized by a considerable stress peak, which may be a result of flow localization. Instability regions also occur for higher true strain values, and for a true strain of 0.9 , they can be observed at a strain rate ranging from 1 to $10 \mathrm{~s}^{-1}$ and at temperature ranges of $800{ }^{\circ} \mathrm{C}$ to $830{ }^{\circ} \mathrm{C}$ and $970{ }^{\circ} \mathrm{C}$ to $1000{ }^{\circ} \mathrm{C}$. Unstable domains indicated that flow localization and ASBs, as well as cracks, may occur. Therefore, a deformation process using parameters from these regions should be avoided.

High $\eta$ parameter values promote the occurrence of superplasticity or DRX phenomena, which result in a fine and homogenous microstructure. Regardless of the true strain value, the efficiency peak was noticed for a strain rate from 0.01 to $0.1 \mathrm{~s}^{-1}$ and a temperature range of $840{ }^{\circ} \mathrm{C}$ to $960{ }^{\circ} \mathrm{C}$, where the efficiency of power dissipation was 46 to 60 pct. Additionally, it was previously reported that for $\beta$ titanium alloys, deformation with low strain rates promotes the occurrence of DRX, due to long enough time for grain refinement. ${ }^{[37]}$
It is worth noting that due to increasing true strain, the high $\eta$ values were in a narrower temperature range. At high strain rates, the $\eta$ parameter was equal to 28 to 32 pct, and in these regions, dissipation may occur by DRV phenomena rather than by DRX. ${ }^{[27]}$

Microstructural observations confirmed the presence of defects for the samples deformed under the processing parameters corresponding to instability regions. At the temperature below the $\beta$-transus, flow localization was the most visible defect. Regarding the fact that titanium exhibits a temperature increase during deformation up to $80^{\circ} \mathrm{C},{ }^{[38]}$ and has a relatively low thermal conductivity, heat stored in deformed material leads to local flow stress reduction, which results in ASB formation along shear stress planes located in relation to the compression axis by about $45 \mathrm{deg}$. The described ASB formation effect along with intergranular crack was observed in the presented research at high temperatures and a strain rate of $10 \mathrm{~s}^{-1}$. Similar results were noted by Sun et al., ${ }^{[39]}$ where such defects were observed for TiAl-based alloy, also obtained by the PM method, which was deformed under the instability region parameters.

The occurrence of defects during hot processing of Ti-10-2-3 alloy compact is consistent with the developed processing maps. Due to a high probability of flow localization, ASB formation, and crack propagation, processing at temperature ranges of $800{ }^{\circ} \mathrm{C}$ to $830{ }^{\circ} \mathrm{C}$ and $970{ }^{\circ} \mathrm{C}$ to $1000{ }^{\circ} \mathrm{C}$ and high strain rates should be avoided. For titanium alloys, a similar processing parameter range was previously reported by Lypchanskyi et al. ${ }^{[25]}$ as unstable. In cited work, processing maps based on Malas's criterion were elaborated for Ti-6246 alloy and microstructural defects in the form of flow localization were also confirmed. Additionally, Chuan and Liang ${ }^{[40]}$ show flow localization at low temperatures and at a strain rate of $10 \mathrm{~s}^{-1}$ for another, Ti-55531 $\beta$ titanium alloy.

\section{Processing Windows}

Based on developed processing maps (Figure 5(c)), hot-deformed material microstructure observations (Figure 7), and hardness measurements (Figure 8), three domains considered as processing windows for Ti-10-2-3 compacts were selected.

Domain I, with a temperature ranging from $850{ }^{\circ} \mathrm{C}$ to $940{ }^{\circ} \mathrm{C}$ and strain rates ranging from 0.01 to $0.05 \mathrm{~s}^{-1}$, represents a combination of process parameters characterized by the highest efficiency of power dissipation. Additionally, the bottom range of the temperature was placed above the $\beta$-transus temperature. Within this domain, effects related to DRX phenomena and extensive $\beta$ grain growth are expected. Microstructure observations confirmed the occurrence of recrystallized grains and a small amount of retained $\alpha$ phase, which could result in a slight increase of hardness. No microstructural defects were found in the investigated alloy. Domain II, for a temperature range of $980{ }^{\circ} \mathrm{C}$ to $1000{ }^{\circ} \mathrm{C}$ and a strain rate ranging from 0.01 to $0.1 \mathrm{~s}^{-1}$, covers the area with relatively high efficiency of power dissipation. Additionally, the microstructure obtained at 
the temperature of $1000{ }^{\circ} \mathrm{C}$ and a strain rate of $0.01 \mathrm{~s}^{-1}$ was characterized by fully recrystallized, equiaxed $\beta$ grains, which replaced the initial microstructure. Domain III is located at the temperature range of $920{ }^{\circ} \mathrm{C}$ to $940{ }^{\circ} \mathrm{C}$ and with strain rates ranging from about 3 to $10 \mathrm{~s}^{-1}$, with a 32 to 36 pct efficiency of power dissipation. The $\eta$ value in this domain indicates the appearance of DRV and DRX phenomena. Therefore, hot deformation in the range of the proposed parameters within domain III may result in the occurrence of fine, equiaxed $\beta$ grains and a small amount of retained $\alpha$ grains. However, due to the tendency of titanium alloys to increase their temperature during hot deformation, ${ }^{[35]}$ the processing at temperatures higher than $940{ }^{\circ} \mathrm{C}$ should be avoided.

Proper selection of favorable processing parameters, based on the development of processing maps, may lead to obtaining a product with homogenous microstructure and profitable mechanical properties. Wojtaszek et al. ${ }^{[14]}$ successfully die forged Ti-10-2-3 alloy compact gear wheel, produced with the same processing route as mentioned earlier in this work. In this study, the parameters of the hot forging process were also developed using finite element method analysis. Scheduled die forging, performed on a hydraulic press at $900{ }^{\circ} \mathrm{C}$, which corresponded to the proposed processing window in domain I, resulted in receiving a product with advantageous microstructure and good mechanical properties. Also, no visible defects or cracks in the processed material were observed. Similar results were noted by Wojtaszek and Śleboda ${ }^{[41]}$ for hot die forging of Ti-6Al-4V compact, produced with the BEPM approach. Adopted parameters were also convergent with those shown in domain I, resulting in obtaining a flange-shaped surface and internal crack-free product, which was confirmed by computed tomography analysis.

\section{CONCLUSIONS}

The flow behavior of Ti-10-2-3 alloy obtained by the PM method during the hot deformation process at various temperatures and strain rates was investigated, and processing maps for this alloy, based on the Prasad stability criterion, were developed.

The main conclusions of this study can be summarized as follows

1. The flow stress behavior of Ti-10-2-3 alloy compact indicated that this material is sensitive to variable parameters of deformation, especially the processing temperature and strain rate. Flow curves obtained for the deformation at lower temperatures and high strain rates were characterized by flow stress peak, followed by flow softening. Increasing the temperature and decreasing the strain rate resulted in more steady-state characteristics of the stress-strain curve.

2. Elaboration of processing maps with indicated instability domains allowed designation of the process parameters, which should be avoided during hot processing of Ti-10-2-3 alloy obtained by the PM method. Such unfavorable processing conditions were determined as processing at the temperatures between $800{ }^{\circ} \mathrm{C}$ and $940{ }^{\circ} \mathrm{C}$ and at a strain rate in the range of 1 to $10 \mathrm{~s}^{-1}$ and also at the temperatures between $960{ }^{\circ} \mathrm{C}$ and $1000{ }^{\circ} \mathrm{C}$ and at a strain rate between 1 and $10 \mathrm{~s}^{-1}$. Most favorable conditions of deformation for the investigated alloy were determined as processing at a temperature of $900{ }^{\circ} \mathrm{C}$ and at a low strain rate.

3. Microstructural analysis proved that deformation of the investigated alloy at the processing parameters corresponding to instability regions may result in microstructural defects, ASBs, or intergranular cracks as well as cracks on the surface of the processed material. On the other hand, deformation in peak efficiency regions should result in the defect-free, homogenous, and recrystallized microstructure of the Ti-10-2-3 alloy product.

4. The conducted research allowed determination of the processing windows for the investigated material. Hot forming under the developed thermomechanical combinations of processing parameters should lead to the Ti-10-2-3 alloy products, obtained by the proposed method based on the PM approach, having a favorable microstructure and profitable mechanical properties.

\section{ACKNOWLEDGMENTS}

The financial support of the Polish Ministry of Science and Higher Education is gratefully acknowledged (AGH-UST statutory Research Project No. 16.16.110.663).

\section{CONFLICT OF INTEREST}

The authors declare that they have no conflict of interest.

\section{OPEN ACCESS}

This article is distributed under the terms of the Creative Commons Attribution 4.0 International License (http://creativecommons.org/licenses/by/4.0/), which permits unrestricted use, distribution, and reproduction in any medium, provided you give appropriate credit to the original author(s) and the source, provide a link to the Creative Commons license, and indicate if changes were made.

\section{REFERENCES}

1. F.W. Chen, G. Xu, X.Y. Zhang, K.C. Zhou, and Y. Cui: J. Alloys Compd., 2017, vol. 702, pp. 352-65.

2. R.R. Boyer and R.D. Briggs: J. Mater. Eng. Perform., 2013, vol. 22 , pp. $2916-20$. 
3. H.P. Chang and Y.C. Tseng: J. Med. Sci., 2018, vol. 34, pp. 202-06.

4. M.T. Mohammed: Int. J. Mod. Sci., 2017, vol. 3, pp. 224-30.

5. M. Jackson, N.G. Jones, D. Dye, and R.J. Dashwood: Mater. Sci. Eng., A, 2009, vol. 501, pp. 248-54.

6. R.R. Boyer: JOM, 2010, vol. 62, pp. 21-24.

7. G. Srinivasu, Y. Natraj, A. Bhattacharjee, T.K. Nandy, and G.V.S. Nageswara Rao: Mater. Des., 2013, vol. 47, pp. 323-30.

8. E. Calvert, B. Wynne, N. Weston, A. Tudball, and M. Jackson: $J$. Mater. Process. Technol., 2018, vol. 254, pp. 158-70.

9. L. Cao, X. Wu, S. Zhu, J. Mei, X. Wu, and C. Bettles: Mater. Sci. Eng., A, 2014, vol. 598, pp. 207-16.

10. N. Perevoshchikova, C.R. Hutchinson, and X. Wu: Mater. Sci. Eng., A, 2016, vol. 657, pp. 371-82.

11. M. Ahmed, D.G. Savvakin, O.M. Ivasishin, and E.V. Pereloma: $J$. Alloys Compd., 2017, vol. 714, pp. 610-18.

12. F. Yang, B. Gabbitas, M. Dore, A. Ogereau, S. Raynova, and L. Bolzoni: Mater. Chem. Phys., 2018, vol. 211, pp. 406-13.

13. G. Abakumov, V. Duz, O. Ivasishirr, V. Moxson, and D. Savvakin: Ti 2011_Proc. 12th World Conf. Titanium, 2012, vol. II, pp. 1639-43.

14. M. Wojtaszek, T. Śleboda, M. Rumiński, and J. Luksza: Appl. Mech. Mater., 2014, vol. 606, pp. 119-23.

15. H. Azizi, H. Zurob, B. Bose, S.R. Ghiaasiaan, X. Wang, S. Coulson, V. Duz, and A.B. Phillion: Addit. Manuf., 2018, vol. 21, pp. 529-35.

16. W. Chen, C. Chen, X. Zi, X. Cheng, X. Zhang, Y.C. Lin, and K. Zhou: Mater. Sci. Eng., A, 2018, vol. 726, pp. 240-50.

17. C. Zopp, S. Blümer, F. Schubert, and L. Kroll: Ain Shams Eng. J., 2017, vol. 8, pp. 475-79.

18. X. Bai, Y. Zhao, W. Zeng, and Z. Jia: Rare Met. Mater. Eng., 2015, vol. 44, pp. 12-17.

19. X. Ma, F. Li, J. Cao, J. Li, Z. Sun, G. Zhu, and S. Zhou: Mater. Sci. Eng., A, 2018, vol. 710, pp. 1-9.

20. M. Ahmed, D. Wexler, G. Casillas, O.M. Ivasishin, and E.V. Pereloma: Acta Mater., 2015, vol. 84, pp. 124-35.

21. M. Ahmed, D. Wexler, G. Casillas, D.G. Savvakin, and E.V. Pereloma: Acta Mater., 2016, vol. 104, pp. 190-200.

22. Y. Li, X. Ou, S. Ni, and M. Song: Mater. Sci. Eng., A, 2019, vol. 742, pp. 390-99.

23. D. Qin, D. Guo, L. Zheng, and Y. Li: J. Alloys Compd., 2018 , vol. 76, pp. 725-31.
24. J. Zhao, J. Zhong, F. Yan, F. Chai, and M. Dargusch: J. Alloys Compd., 2017, vol. 710, pp. 616-27.

25. O. Lypchanskyi, K. Zyguła, T. Śleboda, M. Wojtaszek, and A. Łukaszek Sołek: IOP Conf. Ser.: Mater. Sci. Eng., 2018 vol. 461, p. 012048 .

26. H. Matsumoto, M. Kitamura, Y. Li, Y. Koizumi, and A. Chiba: Mater. Sci. Eng., A, 2014, vol. 611, pp. 337-44.

27. Y.V.R.K. Prasad, H.L. Gegel, S.M. Doraivelu, J.C. Malas, J.T. Morgan, K.A. Lark, and D.R. Barker: Metall. Trans. A, 1984, vol. 15A, pp. 1883-92.

28. J.G. Kaufman: Titanium Alloy Database-Knovel, 2012, https://a pp.knovel.com. Accessed January 2, 2019.

29. Z. Du, S. Jiang, and K. Zhang: Mater. Des., 2015, vol. 86, pp. 464-473.

30. N. Srinivasan, Y.V.R.K. Prasad, and P. Rama Rao: Mater. Sci. Eng., A, 2008, vol. 476, pp. 146-56.

31. Y.C. Lin, J. Huang, D. He, X. Zhang, Q. Wu, L. Wang, C. Chen, and K. Zhou: J. Alloys Compd., 2019, vol. 795, pp. 471-82.

32. F. Chen, G. Xu, X. Zhang, and K. Zhou: Mater. Des., 2017, vol. 130 , pp. $302-16$.

33. T. Saito, H. Takamiya, and T. Furuta: Mater. Sci. Eng., A, 1998, vol. 243, pp. 273-78.

34. I. Philippart and H.J. Rack: Mater. Sci. Eng., A, 1998, vol. 243, pp. 196-200.

35. Q. Wang, Y.C. Lin, Y. Jiang, X. Liu, X. Zhang, D. Chen, C. Chen, and K. Zhou: Mater. Charact., 2019, vol. 151, pp. 358-67.

36. V.V. Balasubrahmanyam and Y.V.R.K. Prasad: Mater. Sci. Eng., $A, 2002$, vol. 336 (1-2), pp. 150-58.

37. Y.C. Lin, J. Huang, H. Li, and D. Chen: Vacuum, 2018, vol. 157, pp. 83-91.

38. S. Nemat-Nasser, W.G. Guo, and J.Y. Cheng: Acta Mater., 1999, vol. 47, pp. 3705-20.

39. Y. Sun, Z. Wan, and J. Ren: Mater. Des., 2015, vol. 86, pp. 922-32.

40. W. Chuan and H. Liang: Vacuum, 2018, vol. 156, pp. 384-401.

41. M. Wojtaszek and T. Sleboda: J. Alloys Compd., 2015, vol. 615, pp. S546-50.

Publisher's Note Springer Nature remains neutral with regard to jurisdictional claims in published maps and institutional affiliations. 